\title{
BMJ Open Well-being, physical fitness and health profile of 10-12 years old boys in relation to leisure-time sports club activities: a cross-sectional study
}

\author{
Malte Nejst Larsen (D , ${ }^{1}$ Mads Madsen, ${ }^{1}$ Rasmus Cyril, ${ }^{1}$ Esben Elholm Madsen, ${ }^{1,2}$ \\ Rune R Lind, ${ }^{1}$ Knud Ryom (D) , ${ }^{3}$ Søren Riis Christiansen (D) , ${ }^{4}$ Anne-Marie Elbe (D) , \\ Peter Krustrup ${ }^{1,6}$
}

To cite: Larsen MN, Madsen M, Cyril $\mathrm{R}$, et al. Well-being, physical fitness and health profile of 10-12 years old boys in relation to leisure-time sports club activities: a crosssectional study. BMJ Open 2021;11:e050194. doi:10.1136/ bmjopen-2021-050194

- Prepublication history for this paper is available online. To view these files, please visit the journal online (http://dx.doi. org/10.1136/bmjopen-2021 050194).

Received 15 February 2021 Accepted 26 0ctober 2021
Check for updates

(C) Author(s) (or their employer(s)) 2021. Re-use permitted under CC BY-NC. No commercial re-use. See rights and permissions. Published by BMJ.

For numbered affiliations see end of article.

Correspondence to Dr Malte Nejst Larsen; mnlarsen@health.sdu.dk

\section{ABSTRACT}

Objectives This study investigated the correlation between sports club activities and well-being and physical health parameters in 10-12 years old boys.

Design Cross sectional.

Setting Danish schools.

Participants 2293 boys took part in the study.

Primary and secondary outcome

measures Questionnaires on participation in sports

clubs and well-being and testing of physical health profile

through measurement of body composition, resting

heart rate (RHR), blood pressure and postural balance,

jump and Yo-Yo IR1C performance. Data were analysed

by participation in sport and according to the five most

frequently reported sports.

Results Boys enrolled in sports clubs had higher physical well-being ( $51.7 \pm 9.7$ vs $45.9 \pm 8.7)$ and psychological well-being ( $53.3 \pm 9.6$ vs $51.4 \pm 10.0)$, experienced more peers and social support $(50.9 \pm 9.9$ vs $48.0 \pm 11.6)$, and had a more positive perception of the school environment $(48.6 \pm 7.5$ vs $45.9 \pm 8.1)$ than boys not involved in sports clubs. In addition, they showed better Yo-Yo IR1C (+46\%), long jump (9\%) and balance test performance $(+20 \%)$.

The boys active in sports clubs had higher relative muscle mass $(+6 \%)$ and lower fat percentage $(-3 \%)$, body mass index $(-6 \%)$ and RHR $(-5 \%)$ compared with boys not involved in sports clubs $(p<0.05)$. Boys enrolled in football clubs had higher aerobic fitness compared with boys not active in clubs $(+11 \%)$, handball players $(+5 \%)$, swimmers $(+8 \%)$ and badminton players $(+7 \%)$. Moreover, the boys enrolled in football clubs had lower fat percentage $(-17 \%)$ and higher relative muscle mass $(+4 \%)$ than swimmers.

Conclusion Boys participating in club-based sports showed markedly higher levels of well-being and better physical health profiles than boys not involved in sports club activities. Footballers had superior aerobic fitness and body composition compared with those active in other sports. Results suggest that sports club activities seem to be beneficial for young boys' well-being, fitness and physical health profile, with the greatest benefits achieved by boys involved in football.
Strengths and limitations of this study

- A strength is the large number of participants, making it possible to evaluate the differences in wellbeing and physical health profile from the five most popular sporting activities among boys, whereas earlier studies have lacked statistical power to detect differences when dividing the sample into more than three groups.

- Even though the participant numbers in the various sporting groups differ, the groups are all large, with a minimum of 79 participants.

- Most areas of the country are represented, with schools from both larger and smaller cities as well as the countryside.

- The cross-sectional design is not able to detect causal relations but gives a snapshot of the results. Furthermore, we did not collect data on the boys' everyday activities, such as active transport, or other social or physical activities, which have a bearing on the daily level of activity and might therefore affect both well-being and physical health.

- Neither do we have any data on how long the boys have participated in sports club activities. More years in a sports club are probably more beneficial to well-being and physical health.

\section{BACKGROUND}

Physical activity (PA) is strongly associated with physiological and mental health benefits for children and adolescents, ${ }^{12}$ and sports clubs are important arenas for children to be physically active.

Participating in a leisure-time sport increases PA in general, but also increases PA in settings outside the particular leisure-time sport. A study by Nielsen $e t a l^{3}$ compared the daily activity level of children participating in different leisure-time sports activities and children with no leisure-time sports club participation. They found that children who played football in a sports club 
(even those who trained only once a week) had a higher daily level of moderate and vigorous PA, and that half of the difference could be explained by higher activity levels during school time. ${ }^{3}$ Children active in leisuretime sports other than football also showed increased PA levels during school breaks and spare time, but only when the children had at least two training sessions per week outside of school. Higher overall PA during school time, however, was not recorded among children for sports other than football.

The literature shows that being overweight in childhood and adolescence is associated with reduced quality of life, especially with regard to physical and psychological well-being, social support and school-related well-being. ${ }^{45}$ The risk of reduced quality of life due to poor well-being is comparable to that of diseases such as diabetes and other chronic conditions, ${ }^{6}$ so it is of great relevance to prevent overweight, for example, by being active in sports, ${ }^{7}$ as well as looking at other aspects of physical health status and well-being given that health status is strongly related to quality of life. ${ }^{8}$ Club participation in popular sports is associated with physical and mental health in Danish 10-12 years old girls. ${ }^{9}$ However, comparable studies focusing on boys and their most popular sports are lacking. It is therefore of great relevance to investigate whether well-being is associated with sports participation among 10-12 years old boys. The age group is of interest, since PA in general decreases during the preteen period and health status is related to the risk of various lifestyle diseases in adulthood. ${ }^{2}$

There are a few studies investigating the association between sports participation and health profile in boys. A cross-sectional study by Wold $e t a l^{10}$ compared a population of football players with an age-representative reference population. The results of the study show that the football population in general shows better self-assessed health. This is also found in a pilot study of the present study, which shows that boys participating in sports in general, and football in particular, have a better overall health profile compared with boys not active in sports clubs. ${ }^{11}$

One way in which sports participation can impact on well-being is via the motivational climate that is created by the coach, often seen in team sports. ${ }^{12}{ }^{13}$ If a motivational sporting climate satisfies players' basic psychological needs for autonomy, competence and social relatedness, as outlined in Deci and Ryan's Self Determination Theory ${ }^{14}$, then well-being can be ensured. A study by Alvarez et al, for example, showed how football training which emphasised the process rather than the result could positively impact players' psychological wellbeing and motivation. ${ }^{15}$ A process-oriented environment focuses on individual effort and development rather than on the result. It also places importance on community and cooperation between participants, ${ }^{15}$ and thereby satisfies participants' basic psychological needs.

The aim of the present study is to investigate the association between participation in leisure-time sports club activities and well-being and physical health parameters in 10-12 years old Danish boys.

\section{METHODS}

We investigated the association between various leisuretime sporting activities and broad-spectrum physiological health, performance and well-being parameters in 10-12 years old boys by conducting a cross-sectional study using a multicomponent testing battery. The testing included measurements of cardiovascular fitness, body composition and functional capacity, and questionnaires including biographical information, leisure-time sports activity and well-being. The testers were blinded to whether or not the boys were active in a sports club. The tests were performed in early autumn (August/ September) or early spring (February, March or April). The present study was conducted from August 2016 to September 2018 as an integrated part of the nationwide ' 11 for Health in Denmark' project, with a specific focus on the baseline results of all participating boys. The study was conducted in collaboration with the Danish Football Association (FA), which issued invitations, by email and phone, to all Danish schools to participate in ' 11 for Health'. The pupils in the participating schools were invited to take part in the scientific measurements in the project and the parents received detailed written and oral information about the study, any possible hazards or discomforts, and the option to withdraw at any time. Written informed parental consent was obtained for all participants.

\section{Patient and public involvement}

As an integrated part of the nationwide 11 for Health in Denmark project, the public was involved in the development of the testing protocol through a sparring group led by the Danish FA. All results will be distributed by email to the participating schools and disseminated through seminars for the relevant professionals and press releases targeting the relevant section of the public, for example, the parents.

\section{Sample}

Boys from the 157 participating schools, geographically spread all over Denmark, were included in the study if they had written consent from their parents and filled out the questionnaire regarding sports participation. Two thousand two hundred ninety-three subjects took part in the study, of which 1854 boys were active in sports clubs and pooled into the all-sports active group (ASA), while 439 were not active in sports clubs and were pooled into the non-sports active group (NSA), see figure 1 for the study flow chart. The ASA boys were on average active $2.2 \pm 0.9$ times a week, with the following weekly attendance for each of the individual sports: football $(n=897)$ $2.5 \pm 0.8$ times per week; team handball $(\mathrm{n}=131) 2.3 \pm 0.7$ times per week; gymnastics $(\mathrm{n}=85) 1.6 \pm 0.8$ per week; swimming $(\mathrm{n}=121) 1.8 \pm 1.1$ per week; and badminton 


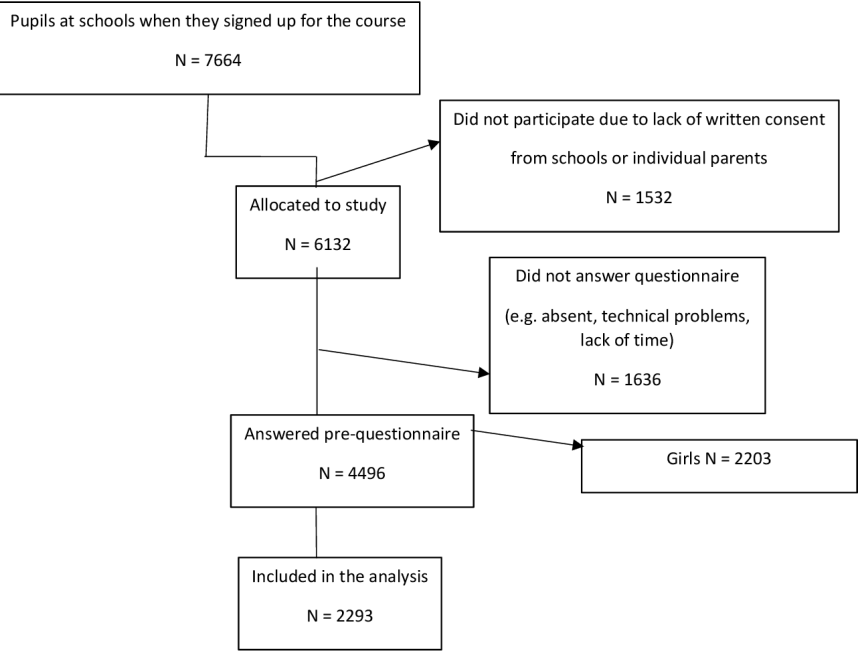

Figure 1 Participants' flow chart.

$(\mathrm{n}=126) 1.4 \pm 0.7$ per week. All data were collected at the participating schools during regular class hours.

Questionnaires on leisure-time sports activity and quality of life The participants' well-being was evaluated using a shortened version of the Danish KIDSCREEN-27 questionnaire. ${ }^{16}$ KIDSCREEN-27 has 27 items within five dimensions: 'physical well-being' ( 5 items); 'psychological well-being' (7 items); 'autonomy and parent relations'; (7 items); 'peers and social support' (4 items); and 'school environment' (4 items). The autonomy and parent relations scale was not considered relevant to the aim of the present investigation and therefore left out to minimise the number of items. The items are rated on a five-point Likert scale ranging from 'never' to 'always' or 'not at all' to 'extremely'. Higher KIDSCREEN-27 scores designate better well-being. The KIDSCREEN-27 questionnaire has shown very good reliability (Cronbach's alphas: 0.800.84 ) and high test-retest reliability. ${ }^{16}$

Leisure-time sports activity, age and gender were identified in the questionnaires. The participants were asked whether they were enrolled in any leisure-time sport (yes/ no). If yes, they were asked to say which sports they were involved in and the number of weekly training sessions. If they were active in more than one leisure-time sport, they were instructed to state the sport they did most often. This part of the questionnaire was a self-developed section but based on a comparable questionnaire that has been used in previous studies in similar age groups. ${ }^{11} 17$

\section{Resting blood pressure and heart rate (HR)}

In a supine position, three blood pressure measurements were taken at approximately $1 \mathrm{~min}$ intervals after $8 \mathrm{~min}$ of initial rest. The measurements were taken in a quiet room on the left upper arm using an automatic blood pressure monitor (M6 HEM-7223-E, Omron, Illinois, USA) with adjusted cuff size. If the first three systolic or diastolic blood pressure (SBP, DBP) measurements varied by more than $10 \mathrm{~mm} \mathrm{Hg}$, an additional measurement was taken.
Resting HR (RHR) was measured at the same time using the automatic blood pressure monitor.

\section{Body composition}

Body mass, muscle mass $(\mathrm{kg})$ and body fat (\%) were measured using an InBody 270 multifrequency body composition analyser (Biospace, California, USA). The subjects were weighed barefoot and in light clothing. The validity and reliability of the InBody 270 compared with Dual-energy X-ray absorptiometry (DXA) scanning in 127 10-12year old girls and boys have shown interclass correlation of 0.99 for fat percentage and 0.97 for muscle mass. ${ }^{9}$ Height was measured with $0.1 \mathrm{~cm}$ precision using a Tanita Leicester portable altimeter (Tanita, Amsterdam, Netherlands).

\section{Muscle strength}

Standing long jump performance (SLJ) was measured following a reduced version of the FIFA 11+ warm up programme, including jumps, as described by Ørntoft et al. ${ }^{11}$ The participants performed two jumps separated by a $5-10 \mathrm{~min}$ rest. The jumps were performed wearing sports shoes or barefoot. The participants stood still with their feet parallel and shoulder-width apart, their toes just behind a line. The children were instructed to bend their knees to a $90^{\circ}$ squat position with their hands placed on their hips and to hold this position for $2 \mathrm{~s}$ before jumping as far as possible, still with their hands on their hips. The distance from the start line to the back heel was measured in centimetres. Each child had two tries 5-10 min apart: the longest jump was reported as the result. The standing long jump is a valid test for children aged 6-17 years, is strongly associated with upper $(\mathrm{r}=0.82-0.86)$ and lower body $(\mathrm{r}=0.69-0.85)$ maximal muscle strength and shows moderate to high reliability. ${ }^{18} 19$

\section{Cardiovascular fitness}

Running performance was evaluated by YYIR1C. The test was performed indoors in a gymnasium. The test consisted of two $16 \mathrm{~m}$ shuttle runs at progressively increasing speeds, separated by $10 \mathrm{~s}$ of jogging after each session of running around a cone placed $4 \mathrm{~m}$ behind the start line. Each run was separated by a beep from an audio device played through loudspeakers. The frequency of the beeps increased throughout the test. The first time the participant failed to make the finish line in time, a warning was given; the second time, the test ended for the participant. Total running distance was recorded. Before the real test, the children were familiarised with the protocol for the test procedure by running the three initial shuttles (also used as a rewarm-up session before the test). Aerobic fitness was estimated from the running distance in the YYIR1C test by the equation: $\mathrm{VO}_{2} \max =0.0116 \mathrm{x}+42.3 \mathrm{~mL} / \mathrm{min} / \mathrm{kg}$, as described by Ahler et al. ${ }^{20}$ The test has been validated in 6-11 yearsold children (coefficient of variation (CV) for 9-11 years old girls: untrained girls $\mathrm{CV}=10.1 \%$, footballplaying girls $\mathrm{CV}=11.5 \%) .{ }^{20} 21$ 


\section{Balance test}

Postural balance was evaluated using the stork balance stand test. ${ }^{22}$ The children stood barefoot and positioned their hands on their hips, then placed their nonsupporting foot on the inside knee of the supporting leg. They then raised their heel to balance on the forefoot.

The time started as the heel was raised from the floor. The timer was stopped if: (1) the hands left the hips; (2) the supporting foot rotated or moved in any direction; (3) the non-supporting foot lost contact with the knee; (4) the heel of the supporting foot touched the floor. The stork balance test has a high test-retest reliability in a fit adolescent population and is valid for evaluating postural balance in young adults. $^{22} 23$

The physiological measurements described above were always performed in the same order, beginning with resting blood pressure, resting HR and InBody measurements, followed by a uniform warm-up, a standing long jump test and the YYIR1C. The testing was conducted by trained test personnel from the university blinded to the children's sports club participation. They were assisted by qualified teachers and/or pedagogues.

\section{Statistical analysis}

Cronbach's alpha scores calculated with SPSS Statistic V.25 (IBM SPSS Statistics) were used to determine the internal consistency of the four well-being scales. Mean and SD were calculated for all test results, age and weekly frequency of participation in sports. Multiple linear regression, in which age was adjusted for, was used to analyse differences between boys active in sports clubs and boys not active in sport clubs. The same statistical analysis was used to investigate differences between the five most popular sports, and here adjusted for both age and frequency of weekly participation. ${ }^{24}$

Data were analysed according to whether the boys participated in leisure-time sport and according to the five most frequently reported sports.

\section{RESULTS}

Boys enrolled in leisure-time sports clubs had higher physical well-being $(51.7 \pm 9.7$ vs $45.9 \pm 8.7)$ and psychological well-being ( $53.3 \pm 9.6$ vs $51.4 \pm 10.0)$, experienced more peer and social support $(50.9 \pm 9.9$ vs $48.0 \pm 11.6)$, and had a more positive perception of the school environment (48.6 \pm 7.5 vs $45.9 \pm 8.1)$. The boys active in sports clubs also had better Yo-Yo IR1C $(+46 \%)$, long jump $(9 \%)$ and balance test performance $(+20 \%)$ than boys not involved in leisure-time sports clubs. The boys active in leisure-time sports clubs had higher relative muscle mass $(+6 \%)$ and lower fat percentage $(-3 \%)$, body mass index $(\mathrm{BMI} ;-6 \%)$ and resting heart rate (RHR; $-5 \%$ ) compared with boys not involved in leisure-time sport $(\mathrm{p}<0.05)$. Boys enrolled in football clubs had higher aerobic fitness compared with boys not active in leisure-time sports clubs $(+11 \%)$, handball players $(+5 \%)$, swimmers $(+8 \%)$ and badminton players $(+7 \%)$. Moreover, the boys enrolled in football clubs had lower fat percentage $(-17 \%)$ and higher relative muscle mass $(+4 \%)$ than swimmers. All results can be found in tables 1 and 2 .

\section{DISCUSSION}

The main finding in the present study was that boys participating in club-based leisure-time sports showed markedly higher levels of well-being and fitness, and better health profiles than boys not involved in any sports club activities. These findings are in line with previous findings from the ' 11 for Health in Europe' pilot study, as well as findings among younger boys in Denmark. ${ }^{11}{ }^{17}$ Boys involved in football had better aerobic fitness and better body composition compared with those active in other sports, which was also seen previously. ${ }^{11}$ Although this cross-sectional study does not describe any causal effects of sports participation, it is interesting that those participating in football have a superior health and performance profile, as well as better well-being scores related to social support and positive school environment, compared with other sports with similar training frequency.

Since the study is cross sectional, we cannot conclude what causes the differences, but the following section will suggest some possible explanations based on the assumptions that there could be different intensity and quality ${ }^{25}$ during training in the clubs and that participation in different sports can lead to different behaviour, including around the training sessions. ${ }^{3}$

\section{Well-being}

The boys who engaged in leisure-time sports club activity had better physical and psychological well-being and reported higher peer and social support and a more positive school environment compared with the boys who were not active in leisure-time sporting activities. The better well-being for the active boys might be caused by a greater amount of moderate to vigorous physical activities, social activities connected to sports club participation, higher self-perception and self-worth, as well as positive perception of the school environment and due to more and better social relations/connections (social capital). A recent paper from the same study found the exact same differences in girls. ${ }^{9}$

For boys playing football, the relationship with peers and social support was superior when compared with the non-sports group, which also confirms findings in girls. The benefits of team versus individual sports have been studied with different outcomes, but overall the psychological outcomes of team sports seem to be more advantageous compared with individual sports. ${ }^{26}$ The feeling of a more positive school environment might be caused by the experiences that skilled players have in physical education classes, but especially also in school breaks, when football and other sports are often played. This also leads to more PA during school time for football players. ${ }^{3}$ And, in addition, boys can experience satisfaction of the basic 


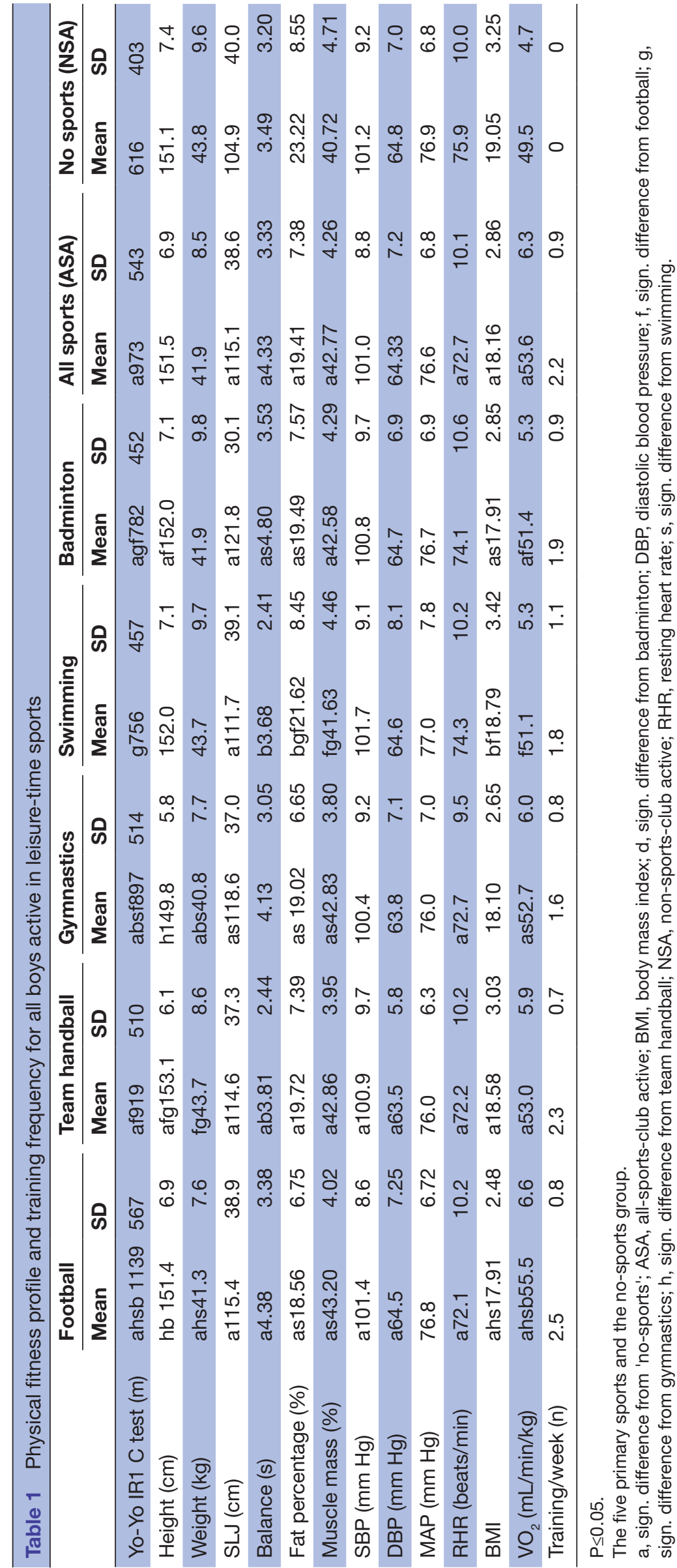


Table 2 KIDSCREEN-27 well-being score for all boys active in leisure-time sports

\begin{tabular}{|c|c|c|c|c|c|c|c|}
\hline $\begin{array}{l}\text { Well-being } \\
\text { measurements }\end{array}$ & $\begin{array}{l}\text { No sports } \\
\text { (NSA) }\end{array}$ & $\begin{array}{l}\text { All sports } \\
\text { (ASA) }\end{array}$ & Football & $\begin{array}{l}\text { Team } \\
\text { handball }\end{array}$ & Gymnastics & Swimming & Badminton \\
\hline \multicolumn{8}{|c|}{ Physical well-being } \\
\hline \multicolumn{8}{|c|}{ Psychological well-being } \\
\hline Mean & $51.4 \pm 10.0$ & $53.3 \pm 9.6 a$ & $54.4 \pm 9.2 \mathrm{ah}$ & $52.4 \pm 10.1 f$ & $53.1 \pm 9.4 \mathrm{fd}$ & $52.3 \pm 9.3$ & $52.9 \pm 9.6$ \\
\hline \multicolumn{8}{|c|}{ School environment } \\
\hline Mean & $45.9 \pm 8.1$ & $48.6 \pm 7.5 a$ & $48.8 \pm 7.2 \mathrm{a}$ & $47.8 \pm 8.1 \mathrm{a}$ & $48.0 \pm 7.5 a$ & $48.2 \pm 7.0 a$ & $49.0 \pm 7.8 a$ \\
\hline
\end{tabular}

Raw means \pm SD.

$\mathrm{P} \leq 0.05$.

The five primary sports and the no-sports group.

a, sign. difference from "no-sports"; ASA, all-sports-club active; d, sign. different from badminton; f, sign. difference from football; g, sign. difference from gymnastics; $h$, sign. difference from team handball; NSA, non-sports-club active; s, sign. difference from swimming.

needs for autonomy, competence and social relatedness, which could explain the higher well-being scores. ${ }^{14}$

In general, the findings support the general assumption that participation in leisure-time sports clubs is associated with higher well-being scores in children. ${ }^{27} 28$

\section{Performance measurements}

Performance in YYIR1C is highly correlated with maximal oxygen uptake measured in the laboratory setting..$^{20}$ As cardiovascular fitness in children and adolescents affects risk factors for future BMI, body fat and metabolic syndrome, good cardiovascular fitness is important for future health. ${ }^{29}$ Boys doing leisure-time sport ran $58 \%$ further in the YYIR1C test, corresponding to $4.1 \mathrm{~mL} / \mathrm{kg}$ / min, than NSA boys, while boys playing football ran 85 , $24,51 \%$ and $64 \%$ further, corresponding to $6.1,2.6,4.4$ and $4.1 \mathrm{~mL} / \mathrm{kg} / \mathrm{min}$, respectively, compared with NSA subjects, handball players, swimmers and badminton players. That boys participating in leisure-time sports have greater cardiovascular fitness than non-active boys were also found in previous small-scale studies in 8-12 years old boys. ${ }^{1117}$ Furthermore, the analysis of the five sports in this study reveals that boys playing football had higher cardiovascular fitness compared with team handball players, swimmers and badminton players, but not gymnasts. The difference in cardiovascular fitness might be due to differences between the sports in training intensity. ${ }^{25}$ We know from previous studies that the intensity in football is high in terms of HR, but we lack measurements for the other sports. ${ }^{25}$ Another reason for the difference in the distance run may be the design of the test, which is favourable to intermittent sports such as football, as it was originally designed for intermittent sports, or the high training frequency among football players.

Boys active in sports clubs jumped further and had better balance than non-active boys. The jump length is well correlated with muscle strength and shows, together with the higher muscle percentage, a better muscular fitness for the ASA boys. ${ }^{18}$ In relation to balance, it is an important parameter in many physical activities, and since competence in activities helps with maintaining motivation, ${ }^{14}$ this might lead to enhanced PA.

\section{Cardiovascular health profile}

RHR was lower for boys active in all sports clubs, as well as in gymnasts, footballers and handball players compared with non-active boys. Previous studies have found comparable differences in RHR and an association between cardiovascular fitness profile and RHR. ${ }^{1117}$

Blood pressure was normotensive for all groups, but diastolic blood pressure was significantly lower for footballers than for non-active boys, while systolic blood pressure was higher in the football players. Both differences are very small $(0.2 \mathrm{~mm} \mathrm{Hg})$ and should be interpreted carefully. The clinical relevance of the difference in blood pressure can be discussed, but blood pressure paths are detectible in childhood and a healthy blood pressure in childhood will follow into adulthood and avert development of hypertension. ${ }^{30}$

Previous cross-sectional studies have not shown any differences in blood pressure or MAP when comparing different sporting groups with inactive school children, ${ }^{11} 17$ so the findings of the present study should ideally be confirmed by studies with similar sample size.

\section{Body composition}

Boys participating in leisure-time sports had lower body mass, BMI and fat percentage, and higher relative muscle percentage, than non-active boys. These differences were also seen in girls ${ }^{9}$ and, as stated there, 'the differences might be explained by the higher level of PA that children enrolled in leisure-time sport have, which is also higher than for children participating in self-organised sports and children who do not participate in sports at all'. ${ }^{31}{ }^{32}$ Gymnasts had the lowest body mass, BMI and fat percentage compared with the other sports, with a 
few exceptions. The differences could be caused by a gymnast's exercises bearing own weight, where low weight is important. On the other hand, swimmers had higher fat and lower muscle percentage compared with boys active in football, badminton and gymnastics, which may be related to a poorer health status, or to a selection bias, since that type of body composition might be an advantage in (long-distance) swimming and swimming training may not have a positive effect on body composition. ${ }^{33}$

\section{Practical implications}

This study revealed that boys participating in leisure-time sports club activities have better health profile, physical capacity and well-being. The results provide specific information regarding sports club activities in Danish boys as a whole, as well as for five popular sporting activities, with football and gymnastics as prominent examples. The results suggest that higher levels of participation in sport possibly improve fitness profiles and well-being and should be considered by parents, politicians and sports organisations. They should ensure that children participate in leisure-time sports, thereby potentially having a positive impact on the health and well-being of future generations. This could be done by introducing sports in schools and by helping challenged families with financing and guidance.

\section{CONCLUSIONS}

Boys participating in club-based leisure-time sports showed markedly higher levels of well-being, and better fitness and health profiles, than boys not involved in any sports club activities. Boys involved in football had better aerobic fitness and better body composition compared with those active in other sports. Therefore, leisure-time sports club activities seem to be both beneficial and important for childhood well-being, fitness and physical health profile, with a team sport like football as a prominent example.

\section{Author affiliations}

${ }^{1}$ Department of Sports Science and Clinical Biomechanics, Sport and Health Sciences Cluster, University of Southern Denmark, Odense, Denmark ${ }^{2}$ Institut for Terapeut- og Jordemoderuddannelser, University College Copenhagen, Kobenhavn, Denmark

${ }^{3}$ Faculty of Health Sciences, Aarhus University, Aarhus, Midtjylland, Denmark ${ }^{4}$ Department of Public Health, Aarhus University, Aarhus, Denmark

${ }^{5}$ Institute of Sport Psychology and Physical Education, Leipzig University Faculty of Sport Science, Leipzig, Sachsen, Germany

${ }^{6}$ Sport and Health Sciences, College of Life and Environmental Sciences, University of Exeter School of Sport and Health Sciences, Exeter, UK

\section{Twitter Malte Nejst Larsen @MalteNejst and Knud Ryom @KnudRyom}

Acknowledgements The authors would like to give special thanks to the pupils, teachers and pedagogues at the participating schools for their contribution. Thanks to the many students and scientific staff who have been involved in the huge number of tests.

Contributors MNL conducted testing, analysed the data, prepared the first draft of the paper, revised the manuscript, and approved the final version of the paper. A-ME contributed to the design of the study, revised the manuscript and approved the final submission. MM, EEM, RC, RRL and KR implemented the intervention, conducted testing, analysed the data, revised the manuscript and approved the final submission. SRC performed the statistical analysis. PK designed the study, applied for funding, implemented the intervention, analysed the data, prepared the first draft of the paper, revised the manuscript and approved the final version of the paper. Pk is the author acting as guarantor.

Funding The Nordea Foundation (95-154-71338), the Danish Football Association (95-154-71361) and Aase and Ejnar Danielsens Foundation (95-154-71318).

Competing interests None declared.

Patient and public involvement Patients and/or the public were involved in the design, or conduct, or reporting, or dissemination plans of this research. Refer to the Methods section for further details.

Patient consent for publication Consent obtained from parent(s)/guardian(s)

Ethics approval The study was approved by the Regional Committees on Health Research Ethics for Copenhagen and Southern Denmark (J.no. H-16026885).

Provenance and peer review Not commissioned; externally peer reviewed.

Data availability statement Data are available upon reasonable request. Data are available upon reasonable request. Deidentified participant data can be shared in respect of data protection and ethical approval. Please contact: 11forhealth@sdu. dk.

Open access This is an open access article distributed in accordance with the Creative Commons Attribution Non Commercial (CC BY-NC 4.0) license, which permits others to distribute, remix, adapt, build upon this work non-commercially, and license their derivative works on different terms, provided the original work is properly cited, appropriate credit is given, any changes made indicated, and the use is non-commercial. See: http://creativecommons.org/licenses/by-nc/4.0/.

\section{ORCID iDs}

Malte Nejst Larsen http://orcid.org/0000-0002-2600-7126

Knud Ryom http://orcid.org/0000-0001-5947-3038

Søren Riis Christiansen http://orcid.org/0000-0002-3206-408X

Anne-Marie Elbe http://orcid.org/0000-0002-8392-2451

\section{REFERENCES}

1 Andersen LB, Harro M, Sardinha LB, et al. Physical activity and clustered cardiovascular risk in children: a cross-sectional study (the European youth heart study). Lancet 2006;368:299-304.

2 Bangsbo J, Krustrup P, Duda J, et al. The Copenhagen consensus conference 2016: children, youth, and physical activity in schools and during leisure time. Br J Sports Med 2016;50:1177-8.

3 Nielsen G, Bugge A, Andersen LB. The influence of club football on children's daily physical activity. Soccer \& Society 2016;17:246-58.

4 Wallander JL, Kerbawy S, Toomey S, et al. Is obesity associated with reduced health-related quality of life in Latino, black and white children in the community? Int J Obes 2013;37:920-5.

5 Meixner L, Cohrdes C, Schienkiewitz A, et al. Health-Related quality of life in children and adolescents with overweight and obesity: results from the German KIGGS survey. BMC Public Health 2020;20:1722.

6 Buttitta M, lliescu C, Rousseau A, et al. Quality of life in overweight and obese children and adolescents: a literature review. Qual Life Res 2014;23:1117-39.

7 Zahner L, Muehlbauer T, Schmid M, et al. Association of sports Club participation with fitness and fatness in children. Med Sci Sports Exerc 2009;41:344-50.

8 Ngamaba KH, Panagioti M, Armitage CJ. How strongly related are health status and subjective well-being? systematic review and meta-analysis. Eur J Public Health 2017;27:879-85.

9 Madsen M. Team sports activity in school and in leisure-time sports clubs for 8-12-year-olds - Exercise intensity and importance for cardiovascular health, fitness, body composition and well-being $[P h D$. University of Southern Denmark, 2020.

10 Wold B, Duda JL, Balaguer I, et al. Comparing self-reported leisuretime physical activity, subjective health, and life satisfaction among youth soccer players and adolescents in a reference sample. Int $J$ Sport Exerc Psychol 2013;11:328-40.

11 Ørntoft C, Larsen MN, Madsen M, et al. Physical fitness and body composition in 10-12-Year-Old Danish children in relation to leisuretime Club-Based sporting activities. Biomed Res Int 2018;2018:1-8.

12 Eime RM, Young JA, Harvey JT, et al. A systematic review of the psychological and social benefits of participation in sport for 
children and adolescents: informing development of a conceptual model of health through sport. Int J Behav Nutr Phys Act 2013;10:98-21.

13 Reinboth M, Duda JL. Perceived motivational climate, need satisfaction and indices of well-being in team sports: a longitudinal perspective. Psychol Sport Exerc 2006;7:269-86.

14 Deci EL, Ryan RM. Self-determination theory: a macrotheory of human motivation, development, and health. Canadian Psychology/ Psychologie canadienne 2008;49:182-5.

15 Alvarez MS, Balaguer I, Castillo I, et al. The coach-created motivational climate, young athletes' well-being, and intentions to continue participation. J Clin Sport Psychol 2012;6:166-79.

16 Ravens-Sieberer U, Herdman M, Devine J, et al. The European KIDSCREEN approach to measure quality of life and well-being in children: development, current application, and future advances. Qual Life Res 2014;23:791-803.

17 Larsen MN, Nielsen CM, Ørntoft Christina Ø, et al. Physical fitness and body composition in 8-10-Year-Old Danish children are associated with sports Club participation. J Strength Cond Res 2017;31:3425-34.

18 Castro-Piñero J, Ortega FB, Artero EG, et al. Assessing muscular strength in youth: usefulness of standing long jump as a general index of muscular fitness. J Strength Cond Res 2010;24:1810-7.

19 Ortega FB, Artero EG, Ruiz JR, et al. Reliability of health-related physical fitness tests in European adolescents. The Helena study. Int J Obes 2008;32 Suppl 5:S49-57.

20 Ahler T, Bendiksen M, Krustrup P, et al. Aerobic fitness testing in 6to 9-year-old children: reliability and validity of a modified Yo-Yo IR1 test and the Andersen test. Eur J Appl Physiol 2012;112:871-6.

21 Póvoas SCA, Castagna C, da Costa Soares JM, et al. Reliability and construct validity of Yo-Yo tests in untrained and Soccer-Trained schoolgirls aged 9-16. Pediatr Exerc Sci 2016;28:321-30.

22 Panta K, Arulsingh W, Raj J. A study to associate the flamingo test and the stork test in measuring static balance on healthy adults. The Foot and Ankle Online Journal 2015;8.
23 Hammami R, Chaouachi A, Makhlouf I, et al. Associations between balance and muscle strength, power performance in male youth athletes of different maturity status. Pediatr Exerc Sci 2016;28:521-34.

24 Montgomery DC, Peck EA, Vining GG. Introduction to linear regression analysis. John Wiley \& Sons, 2012.

25 Bendiksen M, Williams CA, Hornstrup T, et al. Heart rate response and fitness effects of various types of physical education for 8- to 9-year-old schoolchildren. Eur J Sport Sci 2014;14:861-9.

26 Wikman JM, Elsborg P, Ryom K. Psychological benefits of team sport. In: Parnell D, Krustrup P, eds. Sport and health: exploring the current state of play, 2017.

27 Bangsbo J, Krustrup P, Duda J, et al. The Copenhagen consensus conference 2016: children, youth, and physical activity in schools and during leisure time. Br J Sports Med 2016;50:1177-8.

28 Spengler S, Woll A. The more physically active, the healthier? the relationship between physical activity and health-related quality of life in adolescents: the MoMo study. J Phys Act Health 2013;10:708-15.

29 Mintjens S, Menting MD, Daams JG, et al. Cardiorespiratory fitness in childhood and adolescence affects future cardiovascular risk factors: a systematic review of longitudinal studies. Sports Med 2018;48:2577-605.

30 Theodore RF, Broadbent J, Nagin D, et al. Childhood to EarlyMidlife systolic blood pressure trajectories: early-life predictors, effect modifiers, and adult cardiovascular outcomes. Hypertension 2015;66:1108-15.

31 Mooses K, Kull M. The participation in organised sport doubles the odds of meeting physical activity recommendations in 7-12-year-old children. Eur J Sport Sci 2020;20:563-9.

32 Lagestad P, Mikalsen H, Ingulfsvann LS, et al. Associations of participation in organized sport and self-organized physical activity in relation to physical activity level among adolescents. Front Public Health 2019;7:129.

33 Clarke DH, Vaccaro P. The effect of swimming training on muscular performance and body composition in children. Res Q 1979;50:9-17. 